\title{
Clinical Study \\ Utility of Contrast-Enhanced Transabdominal Ultrasonography to Diagnose Early Chronic Pancreatitis
}

\author{
Nobuaki Azemoto, ${ }^{1}$ Teru Kumagi, ${ }^{1,2}$ Tomoyuki Yokota, ${ }^{1,3}$ Masashi Hirooka, ${ }^{1}$ \\ Taira Kuroda, ${ }^{1}$ Mitsuhito Koizumi, ${ }^{1}$ Yoshinori Ohno, ${ }^{1}$ Hirofumi Yamanishi, ${ }^{1}$ \\ Masanori Abe, ${ }^{1}$ Morikazu Onji, ${ }^{1,4}$ and Yoichi Hiasa ${ }^{1}$ \\ ${ }^{1}$ Department of Gastroenterology and Metabology, Ehime University Graduate School of Medicine, Toon, Ehime 791-0295, Japan \\ ${ }^{2}$ Department of Community Medicine, Ehime University Graduate School of Medicine, Toon, Ehime 791-0295, Japan \\ ${ }^{3}$ Center for Liver-Biliary-Pancreatic Diseases, Matsuyama Red Cross Hospital, Matsuyama, Ehime 790-0826, Japan \\ ${ }^{4}$ Internal Medicine, Saiseikai Imabari Hospital, Imabari, Ehime 799-1502, Japan \\ Correspondence should be addressed to Teru Kumagi; terukuma@m.ehime-u.ac.jp
}

Received 28 February 2014; Revised 30 November 2014; Accepted 23 January 2015

Academic Editor: Hui-Xiong Xu

Copyright (C) 2015 Nobuaki Azemoto et al. This is an open access article distributed under the Creative Commons Attribution License, which permits unrestricted use, distribution, and reproduction in any medium, provided the original work is properly cited.

\begin{abstract}
Purpose. The purpose of this study was to establish the relationship between the grade of chronic pancreatitis (CP) and pancreatic blood flow as measured by contrast-enhanced transabdominal ultrasonography (CEUS) and to diagnose early CP easily. Methods. This pilot study was conducted in 8 patients with CP, 7 patients with early CP, and 6 control participants. After injecting $0.015 \mathrm{~mL} / \mathrm{kg}$ of perflubutane by manual bolus, values in one region of interest (ROI) in pancreatic parenchyma and one ROI including the superior mesenteric artery (SMA) were measured. Results. The ratio of blood flow in the SMA and pancreatic parenchyma increased with grade of CP and was significantly higher in patients with $\mathrm{CP}(5.41 ; 2.10-11.02)$ than in patients with early CP $(2.46$; $1.41-5.05)$ and control participants $(2.32 ; 1.25-3.04)(P=0.0279, P=0.0142$, resp.). The ratio of blood flow in the SMA and pancreatic parenchyma correlated with grade of CP ( $\mathrm{rs}=0.5904, P=0.0048)$. Conclusion. The ratio of blood flow correlates with grade of $\mathrm{CP}$ on CEUS. This safe and convenient method may be useful to diagnose early CP.
\end{abstract}

\section{Introduction}

Chronic pancreatitis (CP) is characterized by two distinct features: persistence of inflammation and progressive irreversible fibrosis [1]. Progression of CP leads to development of diabetes mellitus and furthermore pancreatic cancer (PC) [2]. Thus it is clinically important to make a diagnosis of CP at an early stage to prevent its progression and complications. To meet this need, the Japan Pancreas Society (JPS) proposed a new concept called "early CP" in 2009 [3]. However, endoscopic ultrasonography (EUS) and/or endoscopic retrograde cholangiopancreatography are required to diagnose early CP. Recent studies have shown that vascularity on contrastenhanced transabdominal ultrasonography (CEUS) correlates with the pathological grade of fibrosis in patients with autoimmune pancreatitis and PC [4-7]. Previous studies have also demonstrated that CP with advanced fibrosis is associated with reduced blood vessel density and decreased pancreatic blood flow [8-10]. Several studies have correlated the grade of CP (degree of fibrosis) with decreased pancreatic blood flow on dynamic contrast-enhanced magnetic resonance imaging (MRI) [11, 12]. However, the utility of CEUS in identifying degree of fibrosis in $\mathrm{CP}$, especially early $\mathrm{CP}$, remains unclear.

We speculated that CEUS using perflubutane might play a key role in classifying the grade of CP. The purpose of this study was to establish the relationship between the grade of $\mathrm{CP}$ and pancreatic blood flow as measured by CEUS.

\section{Materials and Methods}

This pilot study was conducted with a total of 21 participants at Ehime University Hospital. We classified three categories of $\mathrm{CP}$, early $\mathrm{CP}$, and control according to the criteria of $\mathrm{CP}$ proposed by the JPS. The JPS defined that the criteria comprise 


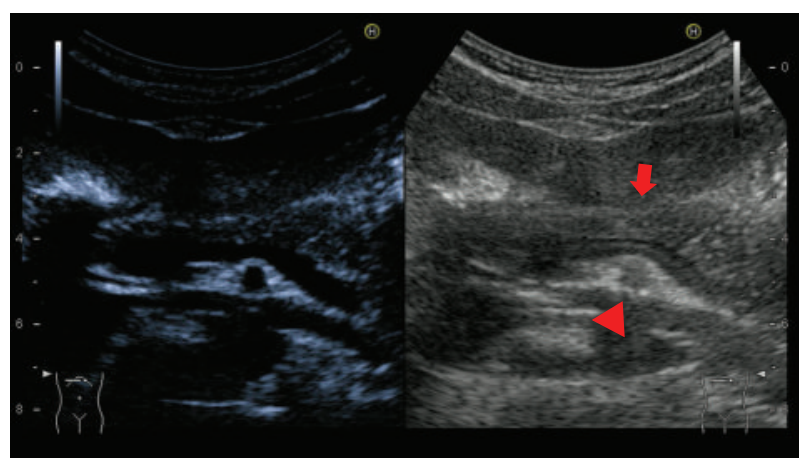

(a)

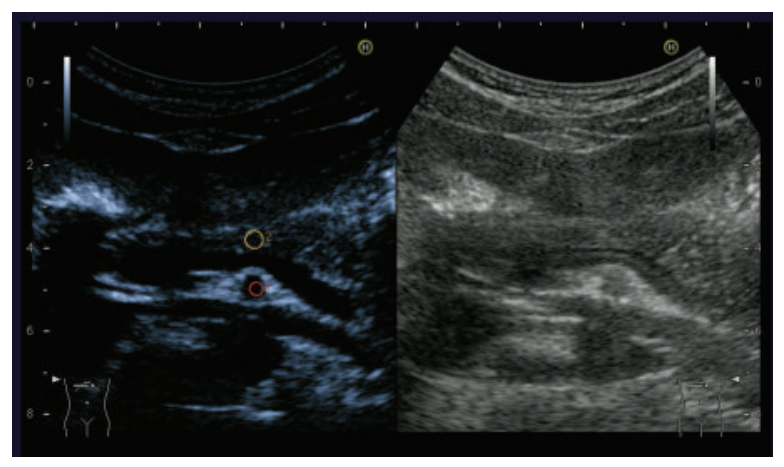

(b)

FIgURE 1: (a) Pancreatic parenchyma (arrow) is visualized together with the superior mesenteric artery (SMA, arrowhead). (b) We defined one region of interest (ROI) in the pancreatic parenchyma and one ROI including the SMA.

six items: (i) characteristic imaging findings, (ii) characteristic histological findings, (iii) repeated upper abdominal pain, (iv) abnormal pancreatic enzyme levels in the serum or urine, (v) abnormal pancreatic exocrine function, and (vi) continuous heavy drinking of alcohol equivalent to or more than $80 \mathrm{~g} /$ day of pure ethanol. Definite and probable findings are set for items (i) and (ii), and the standards are specified for (iv) and (v). Patients with more than two items among (iii), (iv), (v), and (vi) who show EUS or endoscopic retrograde cholangiopancreatography (ERCP) findings of early CP as well are diagnosed with early CP [3]. Twenty-one patients were comprised of 8 patients with $\mathrm{CP}, 7$ patients with early $\mathrm{CP}$, and 6 controls without pancreatic diseases, diabetes mellitus, and alcohol dependency. CP or early CP was diagnosed according to the criteria proposed by the JPS as confirmed by existing results from US, EUS, computed tomography (CT) or MRI, and laboratory tests [3]. Informed consent was obtained from each participant, and the study protocol conformed to the ethical guidelines of the 1975 Declaration of Helsinki. The study protocol was approved by the Local Ethics Committee at the Ehime University Graduate School of Medicine (Approval ID number 1108003).

CEUS was performed by one operator (N.A.), a boardcertified fellow of the Japan Society of Ultrasonics in Medicine, using a Preirus (Hitachi, Tokyo, Japan) and a 3.5 $\mathrm{MHz}$ convex probe in all patients. The protocol for CEUS examinations was based on previous reports $[6,13,14]$. First, it was mandatory that the pancreas was visualized together with the superior mesenteric artery (SMA) (Figure 1(a)). Second, $0.015 \mathrm{~mL} / \mathrm{kg}$ body weight of perflubutane was injected as a manual bolus, followed by a flush of $5.0 \mathrm{~mL}$ of normal saline solution using a $22 \mathrm{G}$ needle into an antecubital or cubital vein. CEUS was conducted in harmonic imaging mode with a low mechanical index $(0.23)$ to avoid bubble disruption. Third, we defined one region of interest (ROI) in pancreatic parenchyma and one ROI including the SMA after the examination. ROIs were selected within the visible area of the pancreatic body. The area of the ROIs ranged from 0.11 to $0.15 \mathrm{~cm}^{2}$ (Figure $1(\mathrm{~b})$ ). Based on the data obtained, maximum and minimum intensity of brightness ( $I_{\max }$ and $\left.I_{\text {min }}\right)$, time to arrival at $I_{\max }\left(T_{\text {arr }}\right)$, and tilt to peak intensity
$\left(V=\left(I_{\max }-I_{\min }\right) / T_{\text {arr }}\right)$ were derived (Figures 2(a) and 2(b)). We next calculated the ratio of $V$ for the SMA $\left(V_{\mathrm{SMA}}\right)$ to $V$ for the pancreatic parenchyma $\left(V_{\text {panc }}\right)$ as $V_{\text {SMA }} / V_{\text {panc }}$, and differences between $\mathrm{CP}$, early $\mathrm{CP}$, and control groups were compared. We then examined correlations between several factors and $V_{\mathrm{SMA}} / V_{\text {panc }}$. We also evaluated the utility of using $V_{\text {SMA }} / V_{\text {panc }}$ to diagnose early CP.

Data collected also included body mass index (BMI), body surface area, pancreatic volume/body surface area (PV/BSA), serum amylase, serum lipase, LDL-cholesterol, triglyceride, serum C-peptide immunoreactivity (CPR) levels, HbAlc (NGSP), and pancreatic function diagnostant (PFD) test.

All statistical analyses were performed using JMP for Windows version 8 software (SAS International, Cary, NC). Continuous variables were expressed as median and ranges. Differences between two groups were analyzed using Wilcoxon rank-sum test. Differences among three groups were analyzed using the Kruskal-Wallis test. Categorical data were analyzed using $\chi^{2}$ test. Correlations between grade of CP and $V_{\mathrm{SMA}} / V_{\text {panc }}$ and between $V_{\mathrm{SMA}} / V_{\text {panc }}$ and various variables were analyzed using nonparametric correlation coefficients (Spearman's $\rho$ ). Two-tailed significance was defined in all analyses as a value of $P<0.05$.

\section{Results}

3.1. Clinical Characteristics of Participants. Clinical characteristics of participants with CP or early CP and controls were shown in Table 1. No significant differences in age, sex, $\mathrm{BMI}$, or pancreatic volume/body surface area were apparent among participants with CP, early CP, and controls. Serum levels of amylase, lipase, LDL-cholesterol, triglyceride, CPR, and HbAlc also were not significant. But PFD test was significantly different among three groups (0.0474).

3.2. Comparison of panc $I_{\text {max }}$, panc $T_{\text {arr }}$, and $V_{\text {panc }}$ according to Grade of CP. $I_{\max }$ for the pancreatic parenchyma ( $\left.{ }_{\text {panc }} I_{\max }\right)$, $T_{\text {arr }}$ for the pancreatic parenchyma $\left({ }_{\text {panc }} T_{\text {arr }}\right)$, and $V_{\text {panc }}$ 
TABLE 1: Clinical characteristics of participants.

\begin{tabular}{|c|c|c|c|c|}
\hline & $\begin{array}{l}\text { Control } \\
(N=6)\end{array}$ & $\begin{array}{c}\text { Early chronic } \\
\text { pancreatitis } \\
(N=7)\end{array}$ & $\begin{array}{l}\text { Chronic pancreatitis } \\
\qquad(N=8)\end{array}$ & $P$ \\
\hline Age & $61.5(28-74)$ & $66(54-69)$ & $58.5(40-67)$ & $0.0913^{*}$ \\
\hline $\operatorname{Sex}(M: F)$ & $5: 1$ & $5: 2$ & $8: 0$ & $0.2826^{* *}$ \\
\hline BMI $\left(\mathrm{kg} / \mathrm{m}^{2}\right)$ & $21.4(18.5-24.5)$ & $21.2(19.7-29.6)$ & $20.8(16.2-26.1)$ & $0.9036^{*}$ \\
\hline Body surface area $\left(\mathrm{m}^{2}\right)$ & $\begin{array}{c}1.56(1.47-1.92) \\
\quad(N=4)\end{array}$ & $\begin{array}{c}1.64(1.44-1.70) \\
(N=7)\end{array}$ & $\begin{array}{c}1.62(1.51-1.79) \\
\quad(N=8)\end{array}$ & $0.6105^{*}$ \\
\hline $\mathrm{PV} / \mathrm{BSA}\left(\mathrm{cm}^{2} / \mathrm{m}^{2}\right)$ & $\begin{array}{c}38.83(36.67-42.56) \\
(N=3)\end{array}$ & $\begin{array}{c}27.26(18.94-46.38) \\
(N=7)\end{array}$ & $\begin{array}{c}19.23(7.48-38.42) \\
(N=8)\end{array}$ & $0.0879^{*}$ \\
\hline Amylase (U/L) & $100(38-170)$ & $105(58-544)$ & $66(33-127)$ & $0.1675^{*}$ \\
\hline Lipase (U/L) & $\begin{array}{c}33(27-52) \\
(N=5)\end{array}$ & $\begin{array}{c}48(32-132) \\
\quad(N=7)\end{array}$ & $\begin{array}{c}21(10-121) \\
(N=8)\end{array}$ & $0.0564^{*}$ \\
\hline LDL-cholesterol (mg/dL) & $125(56-155)$ & $92(60-99)$ & $65(40-127)$ & $0.0901^{*}$ \\
\hline Triglyceride (mg/dL) & $74(41-206)$ & $122(54-399)$ & $72(39-177)$ & $0.2596^{*}$ \\
\hline Serum CPR (ng/mL) & $1.28(0.47-2.53)$ & $2.02(0.17-2.74)$ & $1.55(0.23-3.17)$ & $0.4047^{*}$ \\
\hline HbAlc (\%: NGSP) & $\begin{array}{c}5.7(5.3-6.0) \\
\quad(N=5)\end{array}$ & $\begin{array}{c}5.9(4.7-6.5) \\
(N=7)\end{array}$ & $\begin{array}{c}8.5(5.4-9.4) \\
(N=8)\end{array}$ & $0.0581^{*}$ \\
\hline PFD test (\%) & $\begin{array}{c}72.9(69.6-75.4) \\
(N=5)\end{array}$ & $\begin{array}{c}71.6(60.2-78.0) \\
(N=7)\end{array}$ & $\begin{array}{c}56.3(18.7-72.7) \\
\quad(N=8)\end{array}$ & $0.0474^{*}$ \\
\hline
\end{tabular}

${ }^{*}$ Kruskal-Wallis test, ${ }^{* *} \chi^{2}$ test.

BMI: body mass index, BSA: body surface area, and PV: pancreatic volume.

CPR: C-peptide immunoreactivity and PFD: pancreatic function diagnostant.

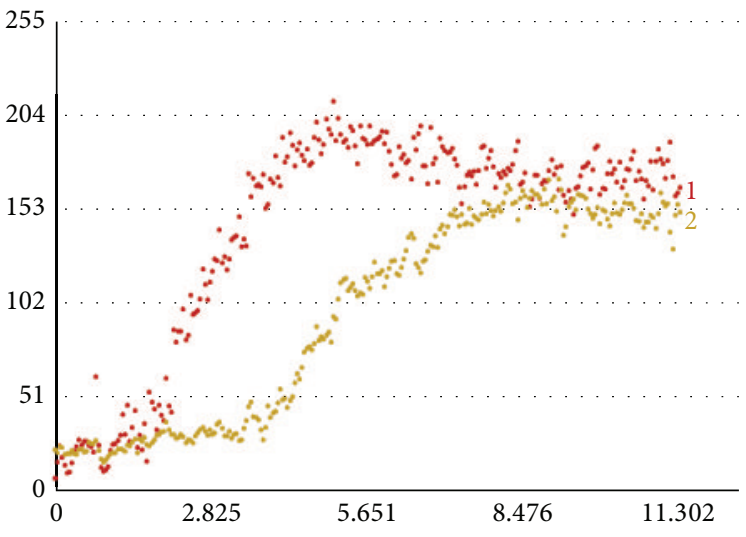

(s)

(a)

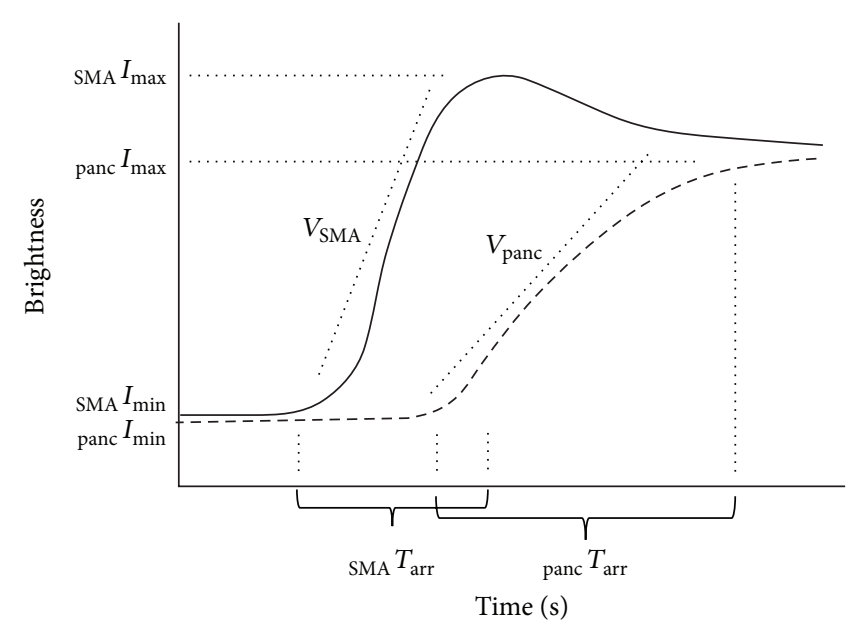

(b)

FIgURE 2: (a) Actual presentation of the time-intensity curve (TIC). (b) Schematic presentation of TIC. $I_{\max }$, maximum intensity of brightness; $I_{\min }$, minimum intensity of brightness; $T_{\text {arr }}$, time to arrival at $I_{\max } ; V$, tilt to peak intensity.

were compared among three groups (Table 2). No significant differences in panc $I_{\max }$, panc $T_{\text {arr }}$, and $V_{\text {panc }}$ were shown.

3.3. Comparison of $V_{S M A} / V_{\text {panc }}$ according to Grade of CP. Values of $V_{\mathrm{SMA}} / V_{\text {panc }}$ increased according to the grade of CP and were significantly different among three groups $(P=0.0209$; Table 3$) . V_{\text {SMA }} / V_{\text {panc }}$ of $\mathrm{CP}$ were significantly higher than those of early CP and control $(P=0.0279, P=0.0142$, resp.). Although values of $V_{\mathrm{SMA}} / V_{\text {panc }}$ did not differ between early $\mathrm{CP}$ and control $(P=0.6682)$, values of $V_{\mathrm{SMA}} / V_{\text {panc }}$ correlated with the grade of CP (Spearman's $\rho$ : rs $=0.5904, P=0.0048$; Figure 3).

3.4. Correlation of $V_{S M A} / V_{\text {panc }}$ and Various Variables. PFD test was the only significant clinical characteristic factor among three groups (Table 1). We investigated the relationship between value of $V_{\mathrm{SMA}} / V_{\text {panc }}$ and PFD test. However, there was no correlation between two factors (Table 4). We also examined the relationship between various variables and value of $V_{\text {SMA }} / V_{\text {panc }}$ (Table 4 ), so that PV/BSA and HbAlc 
TABLE 2: Comparison of panc $I_{\max }$ panc $T_{\text {arr }}$, and $V_{\text {panc }}$ according to grade of chronic pancreatitis.

\begin{tabular}{lccc}
\hline & $\begin{array}{c}\text { Control } \\
(N=6)\end{array}$ & $\begin{array}{c}\text { Early chronic pancreatitis } \\
(N=7)\end{array}$ & $\begin{array}{c}\text { Chronic pancreatitis } \\
(N=8)\end{array}$ \\
\hline panc $I_{\text {max }}$ (brightness $)$ & $113.8(23.4-177.2)$ & $94.8(61.7-193.3)$ & $111.2(51.1-144.7)$ \\
panc $T_{\text {arr }}($ sec $)$ & $4.82(3.02-7.20)$ & $4.90(2.58-7.45)$ & $5.15(3.33-6.87)$ \\
$V_{\text {panc }}$ (brightness/sec) & $22.28(4.04-33.58)$ & $11.40(3.54-35.19)$ & $10.27(5.18-19.64)$ \\
\hline
\end{tabular}

${ }^{*}$ Kruskal-Wallis test.

panc $I_{\max }: I_{\max }$ for the pancreatic parenchyma and $I_{\max }$ and $I_{\min }$ : maximum and minimum intensity of brightness.

panc $T_{\text {arr }}$ : time to arrival at $I_{\max }$ of the pancreatic parenchyma and $T_{\text {arr }}$ : time to arrival at $I_{\max }$.

$V_{\text {panc }}: V$ for the pancreatic parenchyma, $V=\left(I_{\max }-I_{\min }\right) / T_{\text {arr }}$.

TABLE 3: Comparison of $V_{\mathrm{SMA}} / V_{\text {panc }}$ according to grade of chronic pancreatitis.

\begin{tabular}{lccc}
\hline & $\begin{array}{c}\text { Control } \\
(N=6)\end{array}$ & $\begin{array}{c}\text { Early chronic pancreatitis } \\
(N=7)\end{array}$ & $\begin{array}{c}\text { Chronic pancreatitis } \\
(N=8)\end{array}$ \\
\hline$V_{\text {SMA }} / V_{\text {panc }}$ & $2.32(1.25-3.04)$ & $2.46(1.41-5.05)$ & $5.41(2.10-11.02)$ \\
\hline
\end{tabular}

${ }^{*}$ Kruskal-Wallis test.

$V_{\mathrm{SMA}}: V$ for the superior mesenteric artery and $V_{\text {panc }}: V$ for the pancreatic parenchyma.

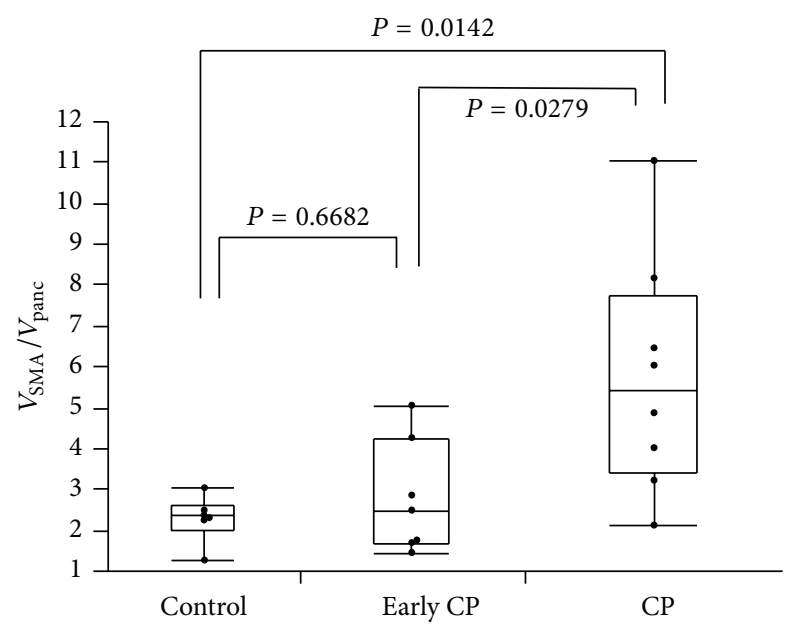

FIgURE 3: The value of $V_{\mathrm{SMA}} / V_{\text {panc }}$ shows the ratio of $V$ for the SMA to $V$ for pancreatic parenchyma and increases according to the grade of CP. Box contains values between 25th and 75th percentiles of the value of $V_{\mathrm{SMA}} / V_{\text {panc }}$ (central line, median). Vertical lines represent minimum and maximum. Values were significantly higher in patients with $\mathrm{CP}$ than in patients with early $\mathrm{CP}$ and controls ( $P=0.0279$ and $P=0.0142$, resp.). The value of $V_{\text {SMA }} / V_{\text {panc }}$ also correlated with the grade of CP (Spearman's $\rho$ : rs $=0.5904, P=$ 0.0048).

were correlated with value of $V_{\mathrm{SMA}} / V_{\text {panc }}(\mathrm{PV} / \mathrm{BSA}$ : $\mathrm{rs}=$ 0.7027, $P=0.0008$, HbAlc: $\mathrm{rs}=0.4244, P=0.0134$; Table 4).

\section{Discussion}

We showed the ratio of blood flow observed by CEUS correlated with progression of CP (Figure 3). Schilling et al. reported that blood flow of the pancreas was significantly diminished in patients with CP [9]. Similarly, a histological study by Angelis et al. found that fibrosis of the pancreas
TABLE 4: Relationship between $V_{\text {SMA }} / V_{\text {panc }}$ and various variables.

\begin{tabular}{lcc}
\hline & rs & $P$ \\
\hline Age & 0.2146 & $0.0913^{*}$ \\
BMI $\left(\mathrm{kg} / \mathrm{m}^{2}\right)$ & 0.0713 & $0.9822^{*}$ \\
Body surface area $\left(\mathrm{m}^{2}\right)$ & 0.0695 & $0.8866^{*}$ \\
PV/BSA $\left(\mathrm{cm}^{2} / \mathrm{m}^{2}\right)$ & 0.7027 & $0.0008^{*}$ \\
Amylase $(\mathrm{U} / \mathrm{L})$ & 0.2316 & $0.1037^{*}$ \\
Lipase $(\mathrm{U} / \mathrm{L})$ & 0.2841 & $0.2288^{*}$ \\
LDL-cholesterol $(\mathrm{mg} / \mathrm{dL})$ & 0.1568 & $0.3331^{*}$ \\
Triglyceride $(\mathrm{mg} / \mathrm{dL})$ & 0.1612 & $0.8165^{*}$ \\
Serum CPR $(\mathrm{ng} / \mathrm{mL})$ & 0.0796 & $0.9688^{*}$ \\
HbAlc $(\%: \mathrm{NGSP})$ & 0.4244 & $0.0134^{*}$ \\
PFD test $(\%)$ & 0.3619 & $0.2156^{*}$ \\
\hline
\end{tabular}

${ }^{*}$ Spearman's $\rho$.

BMI: body mass index, BSA: body surface area, and PV: pancreatic volume. CPR: C-peptide immunoreactivity and PFD: pancreatic function diagnostant.

and changes in blood vessels were observed in $80-100 \%$ and $14-44 \%$ of patients with CP, respectively [8]. However, these studies were conducted among patients with CP showing advanced fibrosis and did not include cases of CP with minimal fibrosis, namely, early CP. Whether these observations are reproducible for early $\mathrm{CP}$ and whether decreased blood flow as well as progression of fibrosis is occurring simultaneously thus remain unclear. The concept of "early CP" was recently proposed by the JPS, in a revision of the diagnostic criteria for CP [3]. Early CP is now defined as a prestage of CP. We demonstrated that blood flow in the pancreas decreases in a stepwise manner concordant with these criteria, and CEUS may thus offer a useful method to classify the degree of CP.

Second, we were indeed able to classify grade of CP by CEUS into groups of CP, early CP, or control (Figure 3 ). We demonstrated that $V_{\mathrm{SMA}} / V_{\text {panc }}$ values increased according to the grade of CP. Values of $V_{\mathrm{SMA}} / V_{\text {panc }}$ were significantly higher in patients with $\mathrm{CP}$ than in patients with early $\mathrm{CP}$ 
and controls $(P=0.0279$ and $P=0.0142$, resp.; Figure 3$)$. Furthermore, we showed that $V_{\mathrm{SMA}} / V_{\text {panc }}$ correlated with pancreatic volume/body surface area and HbAlc, although no significant correlation was between $V_{\mathrm{SMA}} / V_{\text {panc }}$ and PFD test. Serum levels of amylase, lipase, LDL-cholesterol, triglyceride, and CPR also were not significant (Table 4). We speculated that endocrine dysfunction of pancreas gradually decreases according to reduction in pancreatic volume, but exocrine dysfunction decreases suddenly. In this region, values of $V_{\text {SMA }} / V_{\text {panc }}$ were correlated with HbAlc but were not correlated with PFD test.

We demonstrated that CEUS using perflubutane had the potential to allow diagnosis of early CP. Although perflubutane is a frequently used agent, mainly in the diagnosis of liver tumors [13], two reports have shown the utility of this contrast agent in the diagnosis of PC [6] and intraductal papillary mucinous neoplasm [15]. Matsubara et al. also recently showed the utility of perflubutane in the diagnosis of PC using endoscopic ultrasound [14]. However, CEUS using perflubutane had never been studied in terms of the diagnosis of $\mathrm{CP}$ or early CP. CP is a strong risk factor for PC, and the prognosis of PC is extremely poor [2]. Detection of PC as early as possible is thus desirable. However, no strategies to satisfy this need have yet been devised. In the near feature, screening program may be built because enclosure of the high risk group of PC from an early stage is enabled according to diagnosis of early $\mathrm{CP}$ using CEUS.

Several limitations of this study must be kept in mind when interpreting the results. First, the number of participants was small. This may be why we were unable to show any difference in $V_{\text {SMA }} / V_{\text {panc }}$ between patients with early $\mathrm{CP}$ and CP. We should conduct a multicenter study. Second, this method is not applicable for obese individuals, since observing both the pancreas and SMA simultaneously is frequently difficult in such individuals. In contrast, the advantages of this method were simplicity, safety, and convenience.

\section{Conclusion}

The ratio of blood flow on CEUS correlated with grade of CP. This method is safe and convenient. However, larger studies should be conducted in the future to confirm this potential.

\section{Conflict of Interests}

The authors declare that they have no conflict of interests regarding the publication of this paper.

\section{Acknowledgments}

The authors wish to thank Dr. Venessa Pattullo (Storr Liver Unit, University of Sydney at Westmead Hospital, Australia) for English assistance in the preparation of the paper. This work was supported in part by a Grant-in-Aid for Scientific Research (JSPS KAKENHI 23591014, 26461034) from the Japanese Ministry of Education, Culture, Sports, Science, and Technology (to Teru Kumagi).

\section{References}

[1] J. M. Braganza, S. H. Lee, R. F. McCloy, and M. J. McMahon, "Chronic pancreatitis," The Lancet, vol. 377, no. 9772, pp. 11841197, 2011.

[2] S. Raimondi, A. B. Lowenfels, A. M. Morselli-Labate, P. Maisonneuve, and R. Pezzilli, "Pancreatic cancer in chronic pancreatitis; aetiology, incidence, and early detection," Best Practice and Research: Clinical Gastroenterology, vol. 24, no. 3, pp. 349358, 2010.

[3] T. Shimosegawa, K. Kataoka, T. Kamisawa et al., "The revised Japanese clinical diagnostic criteria for chronic pancreatitis," Journal of Gastroenterology, vol. 45, no. 6, pp. 584-591, 2010.

[4] K. Numata, Y. Ozawa, N. Kobayashi et al., "Contrast-enhanced sonography of autoimmune pancreatitis: comparison with pathologic findings," Journal of Ultrasound in Medicine, vol. 23, no. 2, pp. 199-206, 2004.

[5] K. Numata, Y. Ozawa, N. Kobayashi et al., "Contrast-enhanced sonography of pancreatic carcinoma: correlations with pathological findings," Journal of Gastroenterology, vol. 40, no. 6, pp. 631-640, 2005.

[6] S. Kersting, R. Konopke, F. Kersting et al., "Quantitative perfusion analysis of transabdominal contrast-enhanced ultrasonography of pancreatic masses and carcinomas," Gastroenterology, vol. 137, no. 6, pp. 1903-1911, 2009.

[7] M. D’Onofrio, A. Gallotti, F. Principe, and R. P. Mucelli, "Contrast-enhanced ultrasound of the pancreas," World Journal of Radiology, vol. 2, no. 3, pp. 97-102, 2010.

[8] C. de Angelis, G. Valente, M. Spaccapietra et al., "Histological study of alcoholic, nonalcoholic, and obstructive chronic pancreatitis," Pancreas, vol. 7, no. 2, pp. 193-196, 1992.

[9] M. K. Schilling, C. Redaelli, P. U. Reber et al., "Microcirculation in chronic alcoholic pancreatitis: a laser doppler flow study," Pancreas, vol. 19, no. 1, pp. 21-25, 1999.

[10] P. Zhao, J. Tu, J. J. van den Oord, and J. Fevery, "Damage to duct epithelium is necessary to develop progressing lesions of chronic pancreatitis in the cat," Hepato-Gastroenterology, vol. 43, no. 12, pp. 1620-1626, 1996.

[11] X.-M. Zhang, H. Shi, L. Parker, M. Dohke, G. A. Holland, and D. G. Mitchell, "Suspected early or mild chronic pancreatitis: enhancement patterns on gadolinium chelate dynamic MRI," Journal of Magnetic Resonance Imaging, vol. 17, no. 1, pp. 86-94, 2003.

[12] J. Shu, X. M. Zhang, J. N. Zhao, L. Yang, N. L. Zeng, and Z. H. Zhai, "DCE-MRI in experimental chronic pancreatitis," Contrast Media and Molecular Imaging, vol. 4, no. 3, pp. 127-134, 2009.

[13] M. Takahashi, H. Maruyama, H. Ishibashi, M. Yoshikawa, and O. Yokosuka, "Contrast-enhanced ultrasound with perflubutane microbubble agent: evaluation of differentiation of hepatocellular carcinoma," The American Journal of Roentgenology, vol. 196, no. 2, pp. W123-W131, 2011.

[14] H. Matsubara, A. Itoh, H. Kawashima et al., "Dynamic quantitative evaluation of contrast-enhanced endoscopic ultrasonography in the diagnosis of pancreatic diseases," Pancreas, vol. 40, no. 7, pp. 1073-1079, 2011.

[15] H. Sakamoto, M. Kitano, T. Komaki et al., "Small invasive ductal carcinoma of the pancreas distinct from branch duct intraductal papillary mucinous neoplasm," World Journal of Gastroenterology, vol. 15, no. 43, pp. 5489-5492, 2009. 


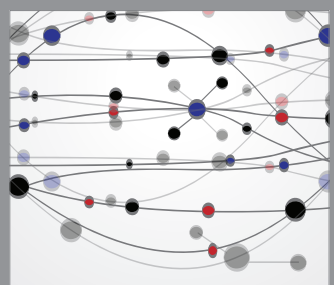

The Scientific World Journal
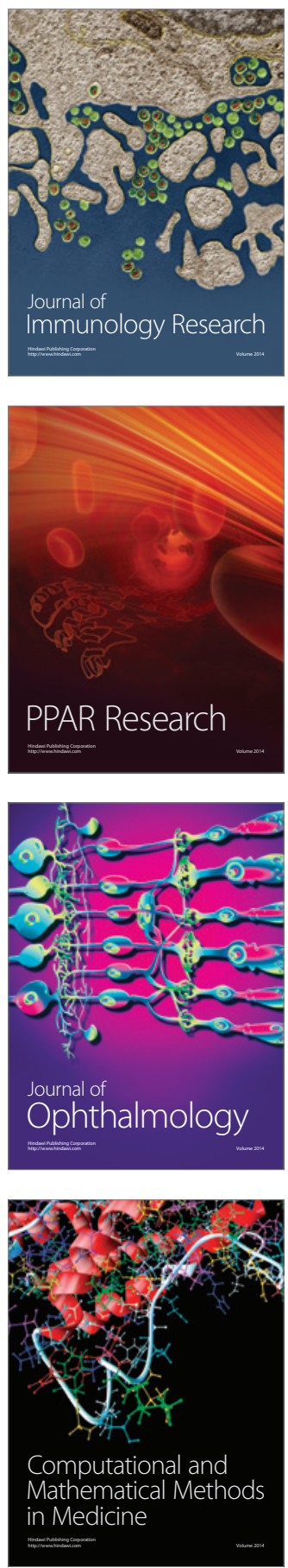

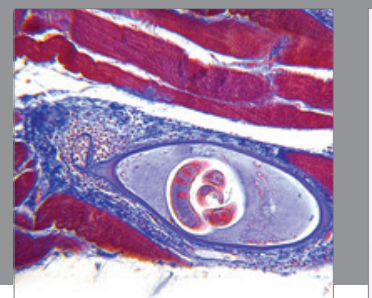

Gastroenterology

Research and Practice
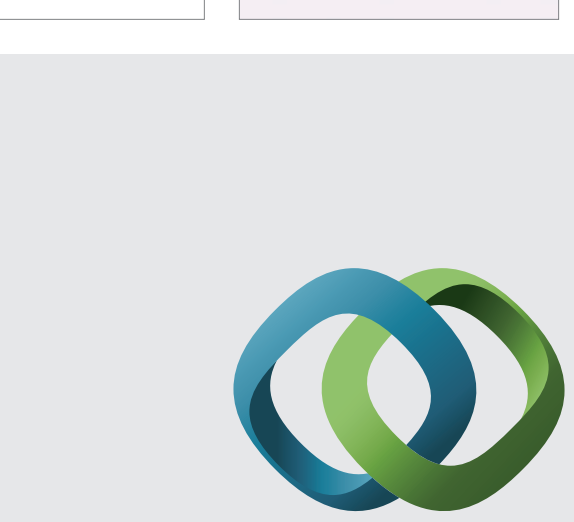

\section{Hindawi}

Submit your manuscripts at

http://www.hindawi.com
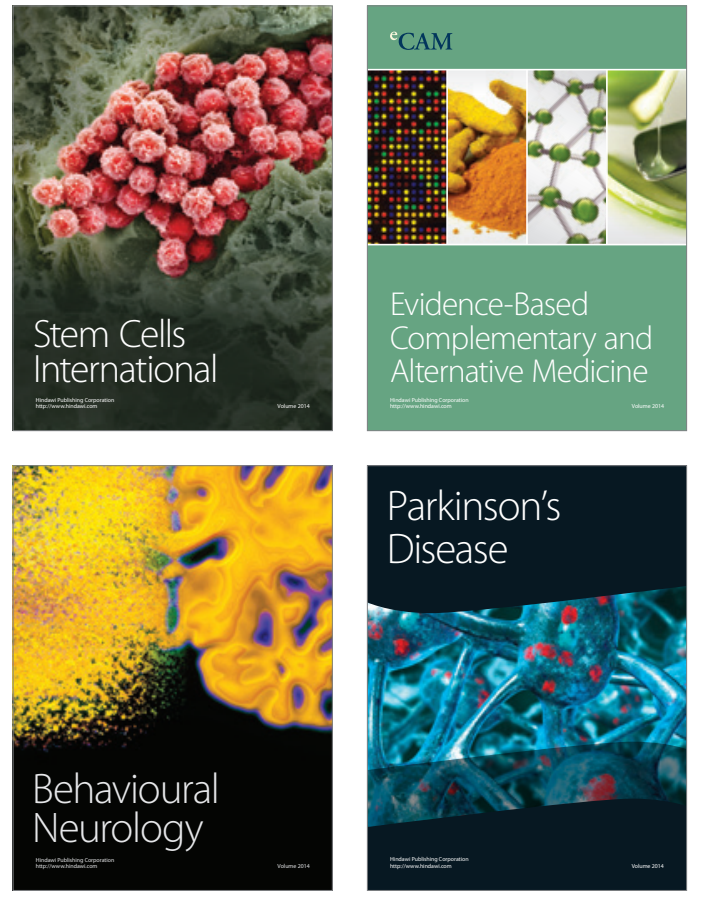
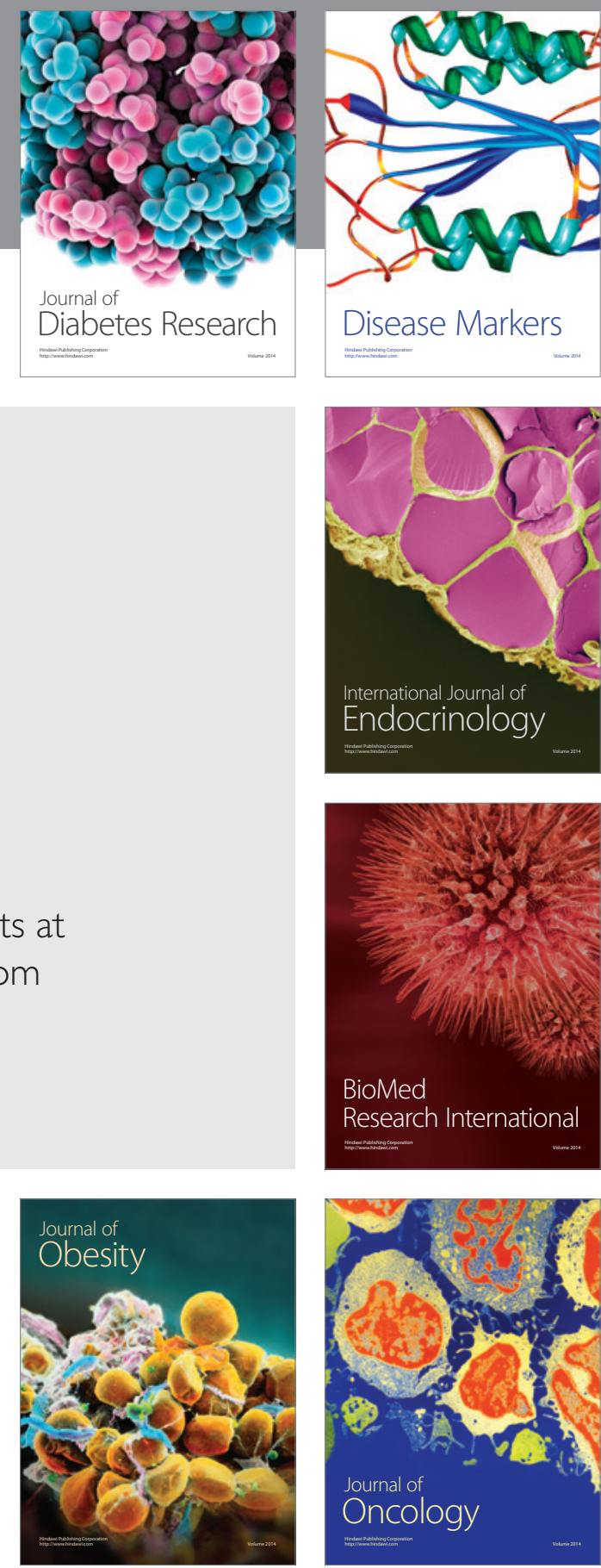

Disease Markers
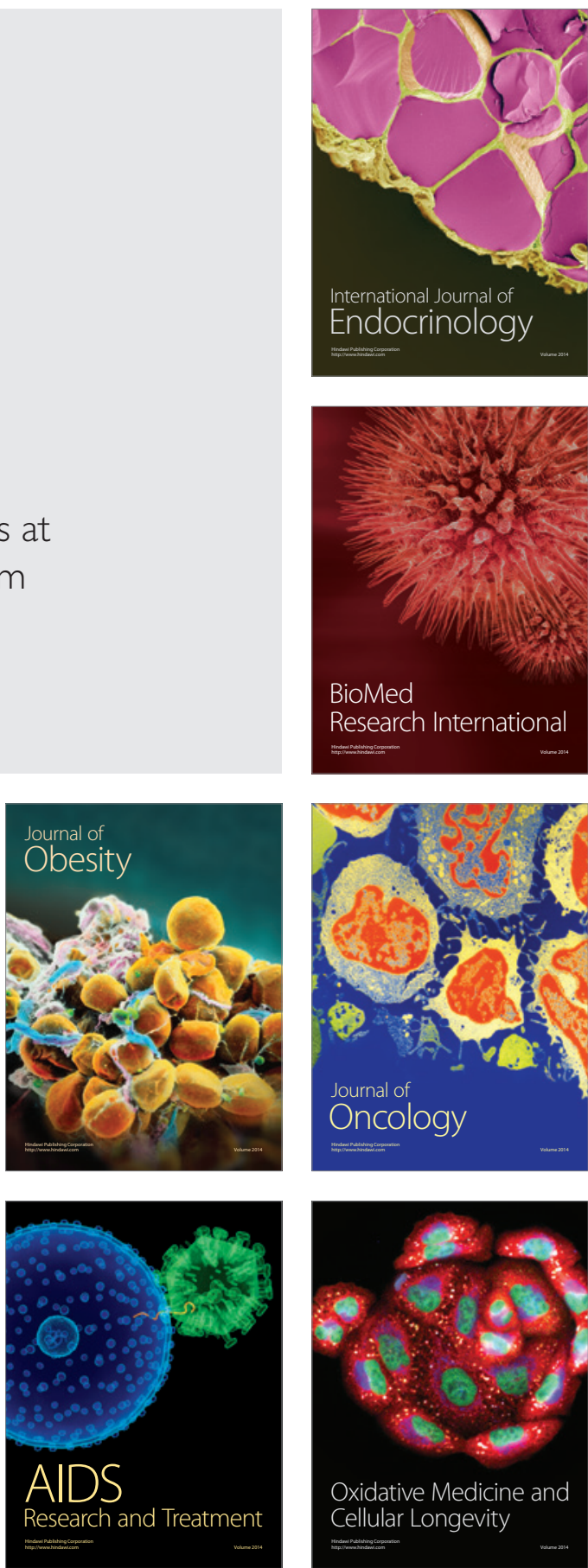